\title{
Propaganda política e a construção da imagem partidária no Brasil
}

\author{
Afonso de Albuquerque \\ Marcia Ribeiro Dias ${ }^{1}$
}

\section{Introdução}

Tradicionalmente, os partidos políticos têm sido considerados como instituições centrais da vida política, intermediários privilegiados das relações que se estabelecem entre os cidadãos e o Estado. Recentemente, porém, diversos autores dão conta de um declínio da importância dos partidos políticos. Quer recorrendo a fórmulas de caráter globalizante - como, por exemplo, Manin (1995) e sua oposição entre "democracia de partidos" e "democracia de público" - ou não, esses autores sugerem que, de maneira crescente, os meios de comunicação de massa têm substituído os partidos como mediadores políticos fundamentais.

Tal via de interpretação é útil à construção de um quadro geral do problema, mas demonstra seus limites quando consideramos o assunto mais detalhadamente. Meios de comunicação e partidos não são instituições que se sucedem no tempo; elas coexistem e estabelecem relações entre si.

Essas relações envolvem, por certo, uma dose de disputa entre as duas instituições, mas não se reduzem a isso. O caso britânico dá conta de uma solução de compromisso na qual a importância crescente dos media como locus e agentes da política não implicou em um enfraquecimento significativo dos partidos

\footnotetext{
${ }^{1}$ Afonso de Albuquerque é doutor em Comunicação Social pela Ufrj e professor do Programa de Pós-Graduação em Comunicação Social da Universidade Federal Fluminense. E-Mail: afonsoal@iis.com.br. Marcia R. Dias é doutora em Ciência Política pelo Iuperj e professora do Programa de Pós-Graduação em Ciências Sociais da Pucrs. E-mail: mrdias@pucrs.br.
} 
políticos e do Parlamento (Blumler, Kavanagh e Nossiter 1996). Sob certas circunstâncias, o uso dos meios de comunicação como recurso político pode, mesmo, servir como fator de fortalecimento, e não de enfraquecimento dos partidos políticos. Acreditamos que seja este o caso do modelo brasileiro de propaganda política na televisão.

Tradicionalmente, o partido político tem sido considerado um elemento frágil na explicação do voto no Brasil. Nesse sentido, tanto a escolha eleitoral apresenta traços acentuadamente personalistas, sendo as taxas de votos de legenda sempre inferiores à incidência de votos nominais, como as campanhas eleitorais da maioria dos partidos políticos centram-se fundamentalmente na imagem do candidato. As pesquisas de opinião também confirmam a preferência dos eleitores brasileiros por critérios de escolha eleitoral relacionados ao perfil do candidato em detrimento de uma escolha partidária. ${ }^{2}$ Além disso, o sistema de lista aberta, que distribui as cadeiras obtidas pelo partido entre seus candidatos mais bem votados, favorece a competição entre os candidatos de um mesmo partido, o que conspira contra a sua unidade.

Em contrapartida, as regras estabelecidas pela legislação brasileira para a propaganda política gratuita na televisão concedem tempo aos partidos e não aos candidatos. Dada a importância da televisão nas campanhas eleitorais, isto pode se constituir em um fator de estímulo à disciplina partidária. Razões de natureza comunicacional também favorecem tal disciplina: em face da enorme diversidade de mensagens que são veiculadas na propaganda política na televisão, é possível supor que partidos capazes de subordinar as mensagens dos seus candidatos a um plano coerente consigam uma vantagem significativa sobre os seus adversários no que concerne à sua visibilidade.

Com base nessas premissas, pretendemos analisar o processo de construção de imagem dos grandes partidos envolvidos na campanha eleitoral de 2002 . Menos do que analisar os traços particulares que caracterizam as campanhas nacionais e regionais dos partidos, interessa-nos investigar a possibilidade de identificarmos traços comuns às suas campanhas. Pretendemos com isso classificar as estratégias eleitorais e apreender o quadro atual da dimensão partidária na propaganda política veiculada na televisão.

$\mathrm{O}$ argumento desenvolvido neste texto desdobra-se em três partes: na primeira discutimos a hipótese segundo a qual os meios de comunicação de massa têm substituído os partidos políticos em uma série de aspectos, como por exemplo, na formação da opinião política; na segunda consideramos aspectos relativos ao sistema eleitoral brasileiro, e os problemas que ele implica do

\footnotetext{
${ }^{2}$ Para resultados eleitorais, ver encartes da Revista Opinião Pública. Para pesquisas de opinião e personalismo no Brasil, ver Silveira (1998).
} 
ponto de vista do voto partidário; na terceira, enfim, damos conta de algumas características fundamentais do modelo brasileiro de propaganda política na televisão e das razões pelas quais elas podem se constituir em um fator de reforço da identidade partidária.

\section{O argumento da substituição e seus limites}

O que denominamos aqui "argumento da substituição" é, na verdade, o produto da convergência de duas linhas de investigação a princípio distintas: a primeira delas refere-se ao declínio dos partidos políticos na arena eleitoral e a segunda, ao aumento da importância política dos meios de comunicação de massa.

\section{Sobre o declínio dos partidos políticos}

Nas democracias contemporâneas, os partidos políticos são organizações que competem eleitoralmente pela conquista de votos e, conseqüentemente, por cargos e prestígio políticos. São instituições políticas da sociedade civil que possuem status diferenciado já que, na maioria das vezes, detêm o monopólio da representação política. O que significa dizer que a filiação a um partido político é critério para a viabilização de projetos políticos, ou para a representação de interesses setoriais que emergem da sociedade, na esfera estatal. Nesse sentido, os partidos agregam um conjunto de propósitos orientados, em maior ou menor grau, por uma ideologia política.

Durante a primeira metade do século XX, os partidos políticos se consolidaram como os atores políticos centrais das principais democracias, na medida em que organizavam as demandas sociais, canalizavam as preferências do eleitorado, viabilizavam soluções para os problemas da organização social através da implementação de políticas públicas e, principalmente, atuavam diretamente na formação da opinião política.

É possível afirmar que os custos da informação política na complexa organização social capitalista representa um dos principais obstáculos à legitimidade dos sistemas democrático representativos. Toda forma de poder estatal legitima-se a partir de alguma crença, mais ou menos enraizada entre os partícipes de uma determinada comunidade política. Assim é que o poder das monarquias absolutistas européias, por exemplo, fundava-se na crença da origem divina do poder dos reis. De forma equivalente, o poder nos sistemas representativos de governo atuais funda-se na crença de que o poder estatal deve ser autorizado pelos indivíduos que sofrem os efeitos de sua atuação.

O mecanismo dessa autorização, consagrado na atualidade, é o da escolha dos representantes pelos representados através de procedimentos eleitorais. $\mathrm{O}$ 
que legitima, portanto, o poder nas modernas democracias é a eleição dos governantes pelos governados. Essa escolha, no entanto, observa limites. O principal deles é o fato, originalmente apontado por Alexis de Tocqueville (1987), de que indivíduos voltados prioritariamente para o seu próprio bem-estar, concentrados nas atividades que garantem a sua sobrevivência ou enriquecimento pessoal, não encontram tempo para se dedicarem aos negócios públicos, tornando alto o custo da informação política.

É importante ressaltar que o desinteresse do eleitor não é a única variável explicativa para o problema dos altos custos da informação política. Essa mesma informação é de natureza complexa: tanto os processos de decisão de políticas públicas, em suas múltiplas ramificações, quanto a rara percepção de seus efeitos pelo eleitor em seu cotidiano, tornam o panorama político envolto em uma névoa que não vale a pena dissipar.

Nesse cenário, a obtenção e sistematização da complexidade e quantidade de informação política necessária a um diagnóstico individual da conjuntura política consiste em um obstáculo ao processo de decisão eleitoral.

Antony Downs, em 1950, procurou abordar esta problemática, traduzida em termos de racionalidade eleitoral, a partir da determinação da funcionalidade dos partidos políticos na decisão do voto. Segundo ele, os partidos políticos reduziriam os custos da obtenção de informação política pelos cidadãos a partir do momento em que processavam a referida informação e orientavam sua atuação por um conjunto básico de princípios ideológicos. Votar em um partido político significaria, portanto, agir racionalmente, e aqui nos referimos a um modelo de racionalidade econômica do voto, na medida em que se reduziriam os custos da participação eleitoral e se ampliariam as possibilidades de obtenção de benefícios da ação governamental (Downs 1999).

Profundas transformações tecnológicas, econômicas, sociais e políticas foram a marca do século mais "curto" de toda a história do mundo ocidental (Hobsbawm 1995). Não é o caso de empreendermos aqui uma longa explanação acerca das características de tais transformações, mas de identificar seus efeitos, no agregado, sobre a função dos partidos como elo de ligação entre governantes e governados.

Alguns fenômenos podem ser associados à redefinição do papel dos partidos nos sistemas representativos contemporâneos. O primeiro deles foi a reestruturação do sistema de classes, marcada pela multiplicação das classes médias em função da ampliação das condições de bem-estar para um número cada vez maior de pessoas. A associação entre partidos e classes, característica dos partidos de massas do início do século, foi progressivamente perdendo o sentido, na medida em que as fronteiras entre as classes se tornaram cada vez mais 
indefinidas. Um outro fenômeno, importante de ser aqui registrado, foi o enfraquecimento dos vínculos de solidariedade social, até mesmo em virtude da própria diluição das identidades de classe.

A resultante desses dois fenômenos relacionados foi a atenuação das posturas ideológicas nos partidos políticos. Se as identidades sociais já não podiam mais ser precisadas, como precisar programas políticos correspondentes? Se, como foi visto inicialmente, o objetivo de todo partido político é chegar ao poder através da competição eleitoral, e assim o é ao menos nas democracias, é natural que a imprecisão ideológica do eleitorado acarrete a imprecisão ideológica dos partidos. Ou seja, a convergência do eleitorado para o centro político, distanciando-se progressivamente dos projetos políticos extremados, foi acompanhada pela tendência centrípeta dos partidos, formando o que a literatura especializada chama de partidos catch-all.

A terminologia utilizada para caracterizar esse tipo de partido fala por si mesma. São partidos que aproximam-se do centro político do eixo ideológico, onde se concentra o maior número de eleitores, a fim de se tornarem aptos às preferências da maioria. Se a maioria é de preferência indefinida, o partido que a representa também o será; afinal, representação também é tradução.

A incidência de partidos catch-all em sistemas multipartidários é menos problemática, pois sempre admite a existência de partidos interessados na representação das minorias que não estão muito próximas ao centro. A situação se agrava quando consideramos sistemas bipartidários. Como nestes casos, o sistema eleitoral geralmente é estritamente majoritário, onde vigora o "jogo de soma zero", a sobrevivência dos partidos dependerá de que eles se tornem catch-all, ou seja, que se tornem aptos à preferência da maioria dos eleitores. $\mathrm{O}$ resultado disso será, certamente, a sub-representação das minorias, colocando em cheque o próprio modelo representativo de governo.

Outro problema grave associado à tendência centrípeta dos partidos políticos é que essas instituições foram perdendo progressivamente seu status na definição do voto. Esse é o principal efeito perverso da "flexibilidade" ideológica dos partidos catch-all; eles acabaram ficando muito parecidos mutuamente, perdendo seu tradicional significado junto aos eleitores. Estes passaram a buscar critérios de diferenciação de propostas políticas no perfil dos candidatos apresentados.

O declínio da importância dos partidos políticos nas democracias contemporâneas é um fenômeno extensivamente estudado nos meios acadêmicos da Ciência Política nacional e, principalmente, internacional. Tal declínio está relacionado tanto ao comportamento eleitoral dos indivíduos, na medida em que o partido político tem sido substituído por outros atributos na escolha do 
eleitor, quanto à redução do potencial de representatividade dos partidos às demandas da sociedade frente ao Estado. Nesse sentido, estudos eleitorais demonstram que o voto se tornou mais personalista, ou seja, relacionado às características pessoais do candidato, ou fruto de issues (questões da pauta pública) selecionadas pelos candidatos em seu programa eleitoral. ${ }^{3}$

Bernard Manin decretou o fim da era dos partidos políticos no modelo de governo representativo, definido a partir de quatro princípios fundamentais: a eleição dos representantes pelos representados; a independência parcial dos representantes com relação à vontade dos representados; a liberdade de opinião pública; e o debate como mecanismo para a tomada de decisão política. Segundo Manin, em mais de um século de funcionamento, esses princípios do modelo representativo de governo mantiveram-se constantes. O objetivo do autor é combater o argumento, amplamente difundido, de que o declínio dos partidos políticos nas democracias contemporâneas representaria uma crise no sistema representativo. Nesse sentido, o sistema representativo independeria da existência de partidos políticos; como agentes do mecanismo de representação, os partidos seriam atores passíveis de substituição sem prejuízo para o sucesso do espetáculo.

Segundo Manin, a "democracia de partido", sucessória do modelo parlamentar, teria sido substituída pela chamada "democracia de público", e seu principal sintoma seria a ampliação da volatilidade eleitoral. Assim, em lugar da identificação partidária, a personalidade dos candidatos passaria a ser determinante na escolha eleitoral. A personalização da representação política, identificada tanto no processo de decisão do voto quanto na dinâmica parlamentar, seria a marca dessa terceira etapa do modelo representativo de governo. A principal causa desta transformação, de acordo com Manin, estaria no desenvolvimento tecnológico dos meios de comunicação, especialmente o rádio e a televisão, que ao aproximar candidato e eleitor dispensaria a atuação dos ativistas partidários.

Autores consagrados da ciência política, como Giovanni Sartori quando se refere à "videopolítica", tendem a partilhar de argumentos semelhantes ao de Bernard Manin. Em essência, o fenômeno do declínio dos partidos nas democracias contemporâneas seria entendido, na interpretação desses autores, nos termos de uma lógica de substituição: suas atribuições clássicas, especialmente a formação da opinião política, estariam sendo assumidas pelos meios de comunicação. Este é o assunto que será abordado no próximo módulo deste trabalho.

\footnotetext{
${ }^{3}$ Bartolini e Mair (1990); Cain, Ferejohn e Fiorina (1987); Daalder e Mair (1983); Katz (1997); Lawson e Merkl (1988); Mair (1997); Samuels (1997); Schmidt (1996) são alguns exemplos de estudos recentes empreendidos neste sentido.
} 


\section{Sobre a importância dos meios de comunicação na dinâmica eleitoral}

Os argumentos acerca do aumento da importância dos meios de comunicação de massa como agentes políticos têm na obra de Walter Lippmann um referencial pioneiro. Contrariando uma perspectiva bem estabelecida no pensamento político norte-americano - segundo a qual uma imprensa livre e atuante constituía uma linha segura de defesa da democracia - Lippmann considerava a atuação da imprensa com grande desconfiança. Segundo ele, uma opinião pública efetiva só pode existir na medida em que o público disponha de representações corretas do mundo. A imprensa, porém, falha em cumprir essa missão devido aos limites temporais e à ausência de métodos sistemáticos no processo de produção de notícias. Em consequiência, as notícias tendem a produzir representações inadequadas, estereotipadas da realidade.

Ecos da sua obra podem ser encontrados em duas correntes teóricas que, por caminhos distintos, destacam a importância dos meios de comunicação de massa no tocante à política. A primeira delas encontra nas obras de autores como Debord (1989) e Baudrillard $(1981,1985)$ seus melhores exemplos. Tais autores descrevem a situação contemporânea nos termos de uma "sociedade do espetáculo" ou uma "era da simulação", na qual uma profusão vertiginosa de imagens e mensagens tecnicamente produzidas e reproduzidas conduz à aniquilação dos referenciais absolutos: "a uma substituição do real por signos do real" (Baudrillard 1981: 11). Os meios de comunicação de massa não atuam nesse cenário, portanto, como instrumentos de construção da realidade, mas sim de dissolução do real. Não é de se espantar que, em um tal contexto, a atuação dos media conduza a uma degeneração da política, tornada puro espetáculo: as entidades políticas fundamentais não são aí, nada mais do que fetiches, "criações dos observadores que dominam e mistificam seus criadores" (Edelman 1988: 11).

A segunda corrente congrega autores identificados com a perspectiva teórica da construção social da realidade - sistematizada por autores como Berger e Luckmann (1973) e Goffman (1986). É importante observar que o termo "construção" não é usado aqui em um sentido negativo, como estereótipos ou simulacros que se oporiam a uma realidade "integral" ou "autêntica". Para Berger e Luckmann, a realidade tal como nós a vivenciamos é socialmente (intersubjetivamente) construída, nas relações que os indivíduos estabelecem quotidianamente entre si. Sendo assim, a construções da realidade podem se opor apenas outras construções da realidade, sem que se possa recorrer a critérios "puramente objetivos" de arbitragem entre elas.

Tanto Berger e Luckmann quanto Goffman concentraram a sua atenção no estudo da comunicação interpessoal, com ênfase para as relações face-à-face. A 
partir do final da década de setenta, porém, diversos autores se valeram dos conceitos por eles desenvolvidos para analisar a atuação dos meios de comunicação de massa no espaço público. Chamou a atenção desses autores o fato de os meios de comunicação de massa - em particular aqueles baseados no princípio do broadcasting (rádio e televisão) - servirem de base à instauração de relações comunicacionais profundamente assimétricas, uma vez que permitiam a um número bastante limitado de agentes veicularem mensagens para um conjunto potencialmente infinito de receptores. Dito de outro modo, o advento dos meios de comunicação favoreceria uma extraordinária concentração da capacidade de definir a realidade, com importantes conseqüências políticas.

Em particular, os autores vinculados à perspectiva da construção social da realidade identificaram três tipos de influência que os meios de comunicação de massa exerceriam sobre o debate público. O primeiro diz respeito à hipótese da agenda setting, segundo a qual os meios de comunicação não têm o poder de determinar o que as pessoas pensam, mas exercem uma influência significativa na seleção dos temas que se tornam objeto do debate público (McCombs e Shaw 1972). O segundo refere-se ao conceito de enquadramentos de media. Desenvolvido inicialmente por Tuchman (1978), ele foi posteriormente sistematizado por Gitlin (1980) como dizendo respeito aos princípios de seleção, ênfase e omissão adotados no processo de produção de notícias, que organizam tanto o trabalho dos jornalistas - permitindo a eles processar rotineiramente uma grande quantidade de informação - quanto a percepção das audiências. Os estudos que se valem deste conceito sugerem que os meios de comunicação influenciam significativamente não apenas a seleção dos temas do debate público, mas também do enfoque adotado acerca deles. Finalmente, o efeito priming refere-se à capacidade dos meios de comunicação de influenciar o processo pelo qual o público julga a responsabilidade dos líderes políticos pelos temas que ganham destaque na esfera pública (Iyengar 1991).

Embora os argumentos relativos ao declínio dos partidos políticos e ao aumento da importância política dos meios de comunicação de massa tenham se desenvolvido de maneira autônoma, diversos autores os têm integrado como elementos de uma mesma equação, que aponta para uma substituição dos partidos pelos meios de comunicação como referenciais fundamentais da vida política. É este o caso de Popkin (1994), Mancini e Swanson (1996) e Manin (1995).

A "hipótese da substituição" se aplica ao argumento desenvolvido por Popkin em seu The rational voter, especialmente quando se considera a reformulação que ele promove no modelo de racionalidade eleitoral de Downs. Analisando o comportamento eleitoral com base no modelo econômico da relação custo/benefício, Downs sustenta que é racional, para os eleitores, evitar des- 
pender muitos recursos na obtenção de informação política uma vez que o voto individual, diluído na massa total de votos, oferece um retorno muito reduzido. Por este motivo, os eleitores se vêem estimulados a recorrer a atalhos cognitivos como a identificação partidária, que poupa os eleitores da necessidade de obter informações mais completas e detalhadas acerca dos candidatos e partidos.

Tal como Downs, Popkin analisa o eleitor como um investidor racional que, baseado em informações custosas e imperfeitas em condições de incerteza, investe em bens coletivos. A questão da relação entre os custos da obtenção da informação política e os benefícios do voto é aqui também importante, mas, ao contrário do que acontece com Downs, não constitui, em si, o problema que se trata de investigar. A questão fundamental de Popkin diz respeito ao modo como essa relação custo/benefício fundamenta o processo de aquisição e processamento de informações e a tomada de decisão do voto, no contexto de uma "racionalidade de baixa informação". Assim como Downs, Popkin, vai recorrer ao conceito de atalho cognitivo para dar conta do problema; diferentemente de Downs, porém, Popkin identifica a campanha eleitoral - e não a identificação partidária - como a principal fonte de tais atalhos cognitivos. Especificamente no que concerne às campanhas recentes, Popkin destaca a importância do papel desempenhado pela televisão, no sentido de favorecer, nas campanhas, um foco nos candidatos enquanto indivíduos, "às expensas dos partidos e das instituições" (Popkin 1994: 90).

Em Mancini e Swanson, por sua vez, o argumento da "substituição" vem associado ao conceito de "modernização" das campanhas eleitorais. Tal modernização, por sua vez, é relacionada ao aumento da complexidade social, isto é, a tendência de substituição das estruturas sociais tradicionais, de caráter agregador, por um conjunto diversificado de microestruturas que produzem realidades simbólicas conflitantes. Aplicada à política, essa situação se traduz no advento de uma nova forma de democracia - a "poliarquia" de Dahl - que passa a ser compreendida como uma arena onde diversos grupos, nem todos de natureza estritamente política (como por exemplo os grupos de interesse), concorrem entre si, emergem os partidos políticos do tipo catch-all e aumenta a importância de figuras políticas individuais em detrimento dos partidos políticos. Neste contexto, os meios de comunicação de massa emergem como um centro autônomo de poder, que concorre com os demais centros, e sua atuação favorece significativamente a personalização da política.

De um modo geral, os modelos explicativos que expusemos aqui fornecem um relato verossímil das transformações que se verificam no âmbito da política em escala global. Toda generalização, porém, apresenta limites, e esses modelos não constituem exceção. No caso do Brasil é no mínimo imprudente estabe- 
lecer uma correlação positiva entre o aumento da importância dos meios de comunicação como locus e como agentes da vida política, e o declínio dos partidos políticos. Em primeiro lugar porque, devido a fatores que detalharemos a seguir, a vida política no Brasil jamais se estruturou em torno de um sistema partidário sólido. Não há, pois, evidências de uma desestruturação, nos dias atuais, de um sistema partidário pré-existente. Ao contrário, acreditamos que o crescimento regular e sistemático do Partido dos Trabalhadores (PT) nas duas últimas décadas é indicativo, em algum grau, de uma tendência de reforço do sistema partidário. Em segundo lugar, porque o modelo brasileiro de propaganda política na televisão atenua os efeitos personalizantes e antiinstitucionais que a bibliografia corrente atribui a este meio de comunicação, uma vez que o tempo para a propaganda política na televisão é fornecido aos partidos políticos e não diretamente aos candidatos.

\section{Estrutura da identificação partidária no Brasil: tendências recentes}

Se fizermos uma retrospectiva do voto no Brasil, desde o período da redemocratização até os nossos dias, perceberemos que os partidos políticos nunca se consolidaram como expoentes da definição eleitoral. No entanto, este não é um fenômeno recente no Brasil. Antônio Lavareda (1989: 181), demonstrou que o sistema de partidos, entre 1945 e 1964, também não apresentava relevância significativa na definição do voto pelos eleitores, embora seu fortalecimento fosse visível ao final do período.

Tradicionalmente no Brasil, pouco se vota em partidos, o que é possível perceber se fizermos um quadro evolutivo das votações de legenda no país. $\mathrm{O}$ eleitor tem preferido a alternativa da votação nominal, ou seja, de escolher, dentro dos partidos, os candidatos que julgam serem capazes de defender seus interesses. É importante também registrar que o movimento das candidaturas em campanhas eleitorais são também essencialmente individualistas, ou seja, valorizam, na maioria das vezes, o perfil do candidato em detrimento da estrutura coletiva partidária. Sendo assim, poucos partidos investem seu arsenal de campanha no estímulo à votação de sua legenda.

Encontramos, desse modo, um personalismo persistente na dinâmica política brasileira que se reforça mutuamente entre representantes e representados. Não sendo a fragilidade dos partidos um fenômeno novo no Brasil, não pode ser explicado por um modelo de "democracia de público", tal como descrevemos acima. Novidade mesmo seria demonstrar o movimento contrário, ou seja, o fortalecimento das identidades partidárias entre os eleitores e a utilização da legenda partidária como recurso para a captação de votos pelas elites políticas. É o que tentaremos fazer a seguir. 
Um interessante trabalho sobre o voto partidário no Brasil foi desenvolvido por David Samuels (1997). O autor mostrou como o sistema eleitoral brasileiro gera incentivos para o personalismo na competição por votos, ao mesmo tempo estratégias de valorização da legenda partidária podem ser bem-sucedidas na captação de votos, como revela o caso do Partidos dos Trabalhadores (PT). O autor analisa os incentivos ao individualismo presentes no formato institucional do sistema eleitoral brasileiro, tentando demonstrar, através do percentual de votos de legenda sobre o número total de votos obtidos por cada partido, entre 1986 e 1994, que a lógica personalista se confirma na prática. Segundo Samuels, "o PT tem sido o único grande partido brasileiro a receber esses votos (de legenda) de modo regular e constante e em alta proporção", consonante com o esforço que o partido faz pela promoção da própria legenda em detrimento da imagem individual de seus candidatos.

Esse diferencial de performance registrado pelo PT nos levou a investigar outros indícios que confirmem o sucesso de sua estratégia coletivista, demonstrando que, contrariamente ao "argumento da substituição", acima desenvolvido, é possível que outros partidos brasileiros venham a assumir uma postura pragmaticamente orientada para a valorização da própria legenda.

Para além da conquista de um significativo percentual de votos de legenda, o PT tem revelado êxito na construção de sua imagem junto ao eleitorado, o que pode ser percebido no números relativos à identificação partidária entre os brasileiros. Assim como foi verificado com os votos de legenda, o PT tem sido o único partido a manter taxas significativamente ascendentes na preferência do eleitorado.

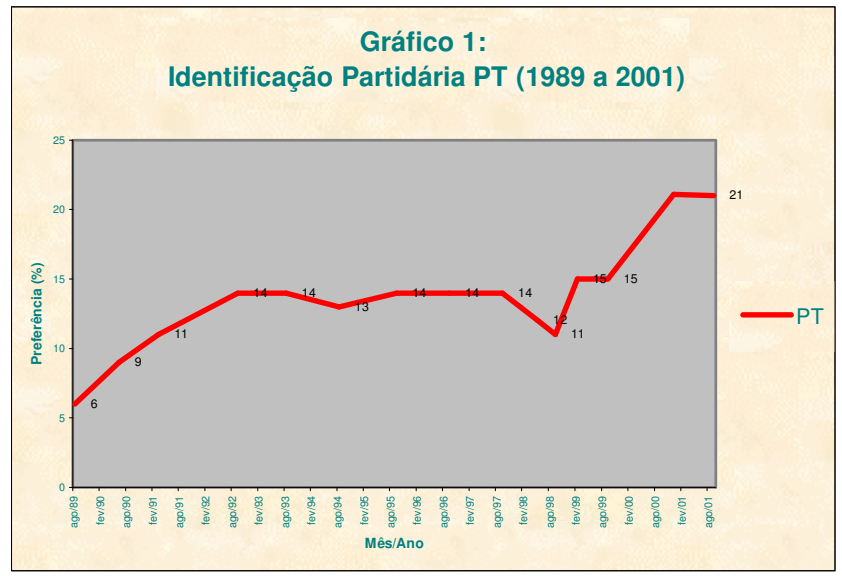

Fonte: Instituto Datafolha 
Como é possível perceber pelo gráfico acima, a identificação partidária com o PT entre os eleitores brasileiros aumentou quase quatro vezes em um período de 12 anos, chegando em 2001 a $21 \%$ da preferência nacional. A curva de identificação com o partido manteve-se ascendente durante quase todo o período, registrando queda apenas em 1994 e 1998, coincidindo com duas derrotas eleitorais para presidente, ainda no primeiro turno, para o PSDB. Este último partido registrou nos mesmos momentos seus picos de popularidade, como pode ser visto pelo gráfico abaixo:

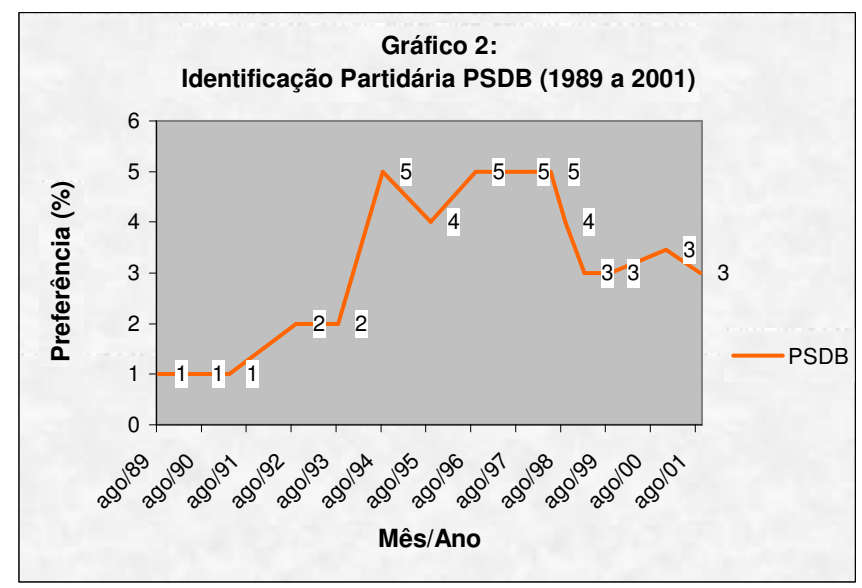

Fonte: Instituto Datafolha

A identificação com o PSDB multiplicou-se por três entre 1989 e 2001, mas em termos percentuais esse crescimento foi pouco significativo: ao final do período apenas $3 \%$ da população identificava-se com o partido. O crescimento é ainda menos significativo se considerarmos o fato de que o PSDB esteve à frente do governo nacional durante 7 dos 12 anos avaliados. Os demais partidos ou mantiveram seus níveis de preferência estáveis, como o PMDB que iniciou e terminou o período com os mesmos $12 \%$, ou declinaram, como o PPB (antigo PDS) que começou com 4\% e chegou a 2001 com 1\% da preferência do eleitorado.

Um outro dado interessante de ser avaliado é o que se refere aos eleitores que não se identificam com nenhum partido. Embora este dado tenha observado uma irregularidade acentuada, considerando-se que em $198962 \%$ dos entrevistados não se identificava com nenhum partido e que em 2001 esse número era de $53 \%$, foi possível perceber um relativo fortalecimento no sistema partidário: $9 \%$ dos eleitores passaram a se identificar com algum partido ao longo do período. Este dado certamente contraria a tese de declínio dos partidos políticos, ao menos no que se refere ao caso brasileiro. Embora mais da metade 
da população ainda não se identifique com nenhum partido, o desempenho do PT demonstrou que esse quadro pode ser revertido.

Se considerarmos a evolução da distribuição partidária de cadeiras na Câmara Federal, vemos que a situação acima se reproduz: apenas o PT e o PSDB mantiveram uma curva ascendente constante entre 1982 e 1998. O gráfico abaixo demonstra o aumento da representação política na Câmara desses dois partidos.

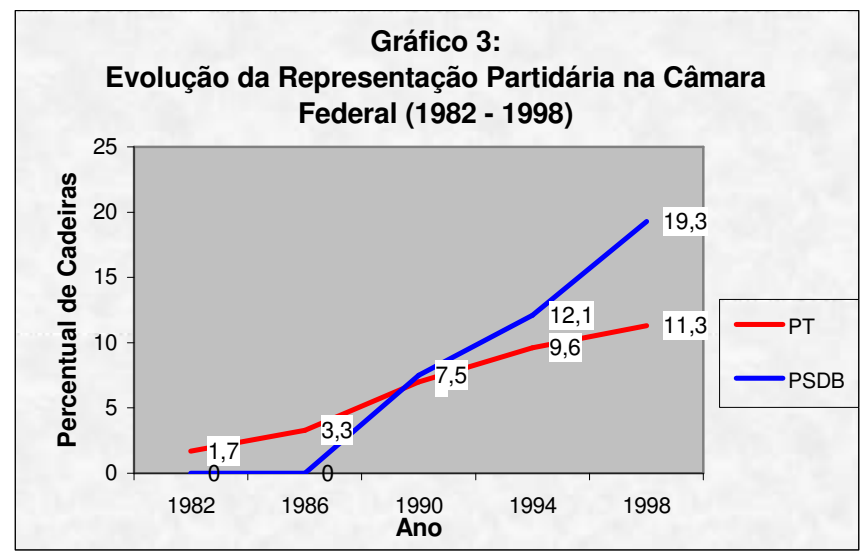

Fonte: Nicolau (1998)

O que mais importa ressaltar com relação a esse gráfico é que apenas esses dois partidos mantiveram-se imunes às oscilações políticas do período, como a entrada de novos competidores através da multiplicação no número de legendas, e continuaram em sua trajetória ascendente. O PSDB, por razões óbvias (seu desempenho eleitoral para o Executivo nacional), observou uma ascensão bem mais acentuada do que o PT. Os outros grandes partidos (PMDB, PFL, PPB, PDT e PTB) apresentaram desempenho irregular, oscilando entre momentos de ascensão e de queda em seus percentuais de cadeiras.

O mais interessante a se notar, entretanto, é a curva de desempenho dos micro partidos, tal como podemos observar a seguir. 


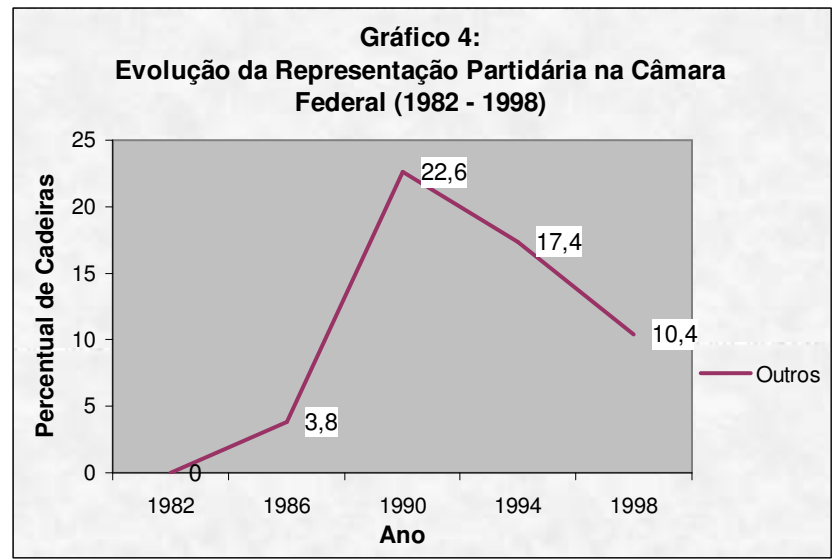

Fonte: Nicolau (1998)

A multiplicação no número de partidos na Câmara Federal iniciou-se nas eleições de 1986, atingindo o seu pico em 1990 quando os micro-partidos somavam juntos $22,6 \%$ das cadeiras parlamentares. É possível afirmar que a volta do multipartidarismo, depois de quase 20 anos de contenção política sob a lógica bipartidária assim como a permissividade da legislação brasileira para a competição eleitoral de partidos com registro provisório (Nicolau 1994) foram responsáveis pelo acentuado aumento no número de partidos com representação parlamentar. Mas seu declínio posterior pode ser considerado um forte indício de consolidação do sistema partidário em torno de sete grandes partidos. Mais uma vez, o caso brasileiro contradiz os rumos apontados pela literatura acadêmica no sentido de um enfraquecimento progressivo dos partidos no sistema representativo contemporâneo.

Discutiremos, a seguir, as principais características do modelo brasileiro de propaganda política, ressaltando novamente os aspectos que tornam a experiência brasileira singular frente à tendência geral apontada pela literatura recente.

\section{O modelo brasileiro de propaganda política na televisão}

A concessão de horário gratuito para a propaganda política na televisão no Brasil remete as suas origens a 1962, mas então o seu impacto eleitoral foi mínimo, dado o subdesenvolvimento desse meio de comunicação. A televisão era, então, um meio fundamentalmente regional e o número de aparelhos receptores no país não atingia a marca dos 2 milhões. O Regime Militar, que se instalou dois anos depois, desempenhou um papel importante na consolidação de uma infra-estrutura nacional de telecomunicações, ao mesmo tempo em que 
relegou as eleições a um papel secundário na vida política nacional. Foi somente a partir de 1985, portanto, que a propaganda política na televisão passou a existir enquanto realidade politicamente relevante. Embora desde então cada eleição tenha sido regulada por uma legislação específica, um conjunto de regras tem se mantido constante desde então: o tempo para a propaganda política é concedido aos partidos políticos, em blocos situados à parte da programação normal (Horário Gratuito de Propaganda Eleitoral ou HGPE), tendo em vista regras que relacionam a quantidade de tempo de que dispõe cada partido à dimensão da(s) sua(s) bancada(s) parlamentar(es) em âmbito federal, estadual ou municipal. Desde 1996, um novo formato foi acrescentado à propaganda política na televisão: os spots de 30 ou 60 segundos, veiculados nos intervalos comerciais ao longo da programação normal.

O modelo brasileiro de propaganda política na televisão possui características únicas: ele combina como nenhum outro eficácia comunicativa com a gratuidade do acesso à televisão. A eficácia comunicativa da propaganda política na televisão se explica em grande medida pelo lugar privilegiado que a televisão ocupa na vida social do país (o que leva alguns autores a caracterizá-lo como uma sociedade media-centric) e é favorecida pela ampla liberdade no uso dos recursos comunicativos da comunicação que, com exceções pontuais, ${ }^{4}$ tem sido contemplada pelas diversas legislações eleitorais desde 1985.

Para lidar com os desafios peculiares ao formato - tais como o isolamento do HGPE em relação à programação normal (e a vulnerabilidade que isto implica com relação à ação dos telespectadores insatisfeitos), a necessidade, que se apresenta para os programas, de adaptar a mensagem a um quadro temporal pré-definido e os problemas decorrentes do excesso de informação devido ao fato de programas de diversos partidos serem apresentados em um mesmo bloco - os programas do HGPE desenvolveram uma gramática própria, baseada na articulação de diversas mensagens em um mesmo programa. Grosso modo, as mensagens que compõem os programas do HGPE cumprem três funções básicas, denominadas através das categorias campanha, metacampanha e auxiliar. As mensagens de campanha têm como objetivo debater temas e apresentar os próprios partido(s) e candidato(s) sob uma luz favorável e os adversários de maneira desfavorável. As mensagens de metacampanha têm como objetivo fornecer relatos sobre a campanha eleitoral, bem como promover o enga-

\footnotetext{
${ }^{4}$ A Lei n. ${ }^{\circ} 8.713$ de 30 de setembro de 1993 proibiu o uso de trucagens, montagens, animações, imagens externas e a presença de outras pessoas que não os próprios candidatos e seus vices nos programas. A justificativa oficial para tais restrições foi que elas possibilitariam uma melhora no nível dos programas do HGPE. Na prática, elas implicaram em uma marginalização do HGPE na campanha eleitoral, o que favoreceu a candidatura de Fernando Henrique Cardoso, apresentado pela imprensa como o grande responsável pelo sucesso do Plano Real (cf. Albuquerque 1995; Miguel 1997).
} 
jamento dos telespectadores no esforço de campanha. As mensagens auxiliares, por sua vez, se destinam a estruturar a propaganda do(s) partido(s) e candidato(s) como um programa de televisão, bem como ajudar a fornecer uma unidade estilística a esses programas (Albuquerque 1999).

Ainda que bastante sumária, uma tal apresentação do modelo brasileiro de propaganda política na televisão é necessária para demonstrar que a intervenção da televisão nas campanhas eleitorais não se processa da mesma maneira em toda parte: Daí porque generalizações sobre o impacto da televisão sobre o sistema político têm necessariamente valor limitado.

Qual é, então, o impacto do modelo brasileiro de propaganda política na televisão sobre o sistema partidário? Contrariando expectativas correntes, sustentamos que, sob diversos aspectos, ele pode se constituir como fator de fortalecimento, antes que de enfraquecimento do sistema partidário.

De diferentes maneiras, o fato de o tempo na televisão ser concedido aos partidos políticos pode contrabalançar as tendências individualistas alimentadas pelo modelo eleitoral brasileiro. Embora a propaganda política na televisão não seja capaz de, por si só, contrabalançar a competição intra-partidária que o modelo eleitoral estimula, ela atua no sentido de subordinar as estratégias individuais dos candidatos a estratégias coletivas dos partidos. As regras do jogo atribuem aos dirigentes partidários o poder de determinar quais candidatos terão acesso à televisão e em que condições: de quanto tempo cada candidato disporá ou se ele receberá alguma forma de tratamento especial (ter o seu nome recomendado por uma liderança do partido, receber um tratamento audiovisual distinto).

$\mathrm{O}$ assunto não se esgota no tratamento dispensado aos candidatos individualmente, mas contempla a possibilidade de os partidos estabelecerem estratégias gerais de ocupação do espaço mediático. Tais estratégias não necessariamente têm como prioridade a maximização dos votos no partido; freqüentemente elas atendem a demandas decorrentes de barganhas intra-partidárias. Assim, os programas podem adotar uma divisão igualitária do tempo entre seus candidatos, equilibrar o tempo entre as facções mais importantes do partido, marginalizar facções dissidentes, montar uma estratégia baseada em "puxadores de votos" etc. Além disso, os partidos podem apostar no voto de legenda e dedicar uma porção significativa dos seus programas à construção da imagem partidária, independentemente da referência a candidatos específicos.

A conquista de mais tempo na televisão - particularmente para candidatos a eleições majoritárias - tem se constituído, juntamente com a construção de uma base parlamentar que garanta a governabilidade do candidato eleito, como um dos principais fatores de estímulo à construção de coligações partidárias. Mesmo quando tais coligações se originam de cálculos oportunistas, a sua edifica- 
ção se apresenta, para os partidos envolvidos, como ocasiões privilegiadas nas quais eles renegociam interna e externamente a sua identidade política.

\section{Considerações finais}

Este texto objetiva lançar as bases de uma pesquisa interdisciplinar e interinstitucional, que visa recuperar a construção da imagem partidária no horário gratuito de propaganda eleitoral. Nosso objetivo é verificar em que medida é possível identificar e classificar distintas estratégias discursivas, entre partidos e campanhas, para a captação de votos. Nossa hipótese é a de um progressivo fortalecimento das estratégias coletivistas entre os grandes partidos brasileiros.

Nosso objetivo, com esse passo inicial, foi demonstrar que a tese de um irreversível declínio dos partidos políticos na dinâmica representativa, e de sua substituição pelos meios de comunicação, pode ser inadequada para explicar o caso brasileiro, tanto pelos fatores personalistas de nossa cultura política, quanto pelo formato institucional da propaganda política na televisão. Além disso, ressaltamos algumas evidências que podem nos levar a uma trajetória inversa à que tem sido assumida pela literatura especializada, apontando para um fortalecimento do sistema de partidos tanto na esfera eleitoral quanto representativa.

\section{Referências bibliográficas}

Albuquerque, Afonso de (1995). Política versus televisão: o horário gratuito na campanha presidencial de 1994. Comunicação \& Política, n. s., v. 1, nº 3, p. 49-54.

Albuquerque, Afonso de (1999). Aqui você vê a verdade na tevê: a propaganda política na televisão. Niterói: MCII (Publicações do Mestrado em Comunicação, Imagem e Informação).

Bartolini, Stefano e Peter Mair (1990). Identity, Competition and electoral availability: the stabilisation of European electorates, 1885-1995. Cambridge: Cambridge University Press.

Baudrillard, Jean (1981). Simulacres et simulation. Paris: Galilée.

(1985). À sombra das maiorias silenciosas: o fim do social e o surgimento das massas. São Paulo: Brasiliense.

Berger, Peter e Thomas Luckmann (1973). A construção social da realidade: tratado de sociologia do conhecimento. Petrópolis: Vozes.

Blumler, Jay G. et al. (1996). Modern Communications versus traditional politics in Britain: unstable marriage of convenience. In: David L. Swanson e Paolo Mancini. Politics, media and modern democracy: an international study of innovations in electoral campaigning and their consequences. Westport/London: Praeger, p. 49-72.

Cain, Bruce, Ferejohn, John e Morris Fiorina (1987). The Personal vote: constituency service and electoral independence. Cambridge: Harvard University Press.

Daalder, H. e P. Mair (1983). Western European party system: continuity and change. London: Sage Publications. 
Debord, Jean (1989). La societé du spectacle. Paris: Éditions Gérard Lebovici.

Downs, Antony (1999). Uma Teoria econômica da democracia. São Paulo: Edusp.

Edelman, Murray (1988). Constructing the political spectacle. Chicago/London: University of Chicago Press.

Gitlin, Todd (1980). The whole world is watching: mass media in the making \& unmaking of the new left. Berkeley: University of California Press.

Goffman, Erving (1986). Frame analysis: an essay on the organization of experience. Boston: Northeastern University Press.

Hobsbaum, Eric (1995). A era dos extremos: o breve século XX - 1914 a 1991. São Paulo: Companhia das Letras.

Iyengar, Shanto (1991). Is anyone responsible? How television frames political issues. Chicago and London: University of Chicago Press.

Katz, Richard (1997). Democracy and elections. Oxford: Oxford University Press.

Lawson, Kay e Peter Merkl (1988). When parties fail: emerging alternative organizations. Princeton: Princeton University Press.

Lavareda, Antônio (1999). A democracia nas urnas. Rio de Janeiro: Revan.

Mair, Peter (1997). Party system change. Oxford: Oxford University Press.

Mancini, Paolo e David L. Swanson (1996). Politics, media, and modern democracy: introduction. In: David L. Swanson e Paolo Mancini. Politics, media and modern democracy: an international study of innovations in electoral campaigning and their consequences. Westport/London: Praeger, p. 1-26.

Manin, Bernard (1995). As metamorfoses do governo representativo. Revista Brasileira de Ciências Sociais, v. 10, n. ${ }^{\circ} 29$, p. 5-34.

McCombs, Maxwell e Donald Shaw (1972). The agenda-setting function of mass media. Public Opinion Quarterly, v. 36, p. 176-187.

Miguel, Luís Felipe (1997). Mídia e discurso político nas eleições presidenciais de 1994. Comunicação \& Política, n. s., v. 4, n. ${ }^{\circ} 1$, jan.-abr., p. 80-97.

Nicolau, Jairo M. (1994). Multipartidarismo e democracia. Rio de Janeiro: Editora da FGV.

(org.) (1998). Dados eleitorais do Brasil (1982-1996). Rio de Janeiro: Revan.

Popkin, Samuel (1994). The reasoning voter: communication and persuasion in presidential campaigns. Chicago: The University of Chicago Press. 2. ed.

Samuels, David (1997). Determinantes do voto partidário em sistemas eleitorais centrados no candidato: evidências sobre o Brasil. Dados, v. 40, n. ${ }^{\circ} 3$, p. 493-533.

Schmidt, Manfred (1996). When parties matter: a review of the possibilities and limits of partisan influence on public policy. European Journal of Political Research, v. 30, n. 2, p. 155-183.

Silveira, Flavio E. (1998). A decisão do voto no Brasil. Porto Alegre: Edipucrs.

Tocqueville, Alexis de (1987). A democracia na América. Belo Horizonte: Itatiaia/Edusp.

Tuchman, Gaye (1978). Making news: a study in the construction of reality. New York: The Free Press. 